\title{
Ionic Liquid Based Vilsmeier Reagent as a Substitute for Mitsunobu Reagent: Direct Conversion of Alcohols into Different Compounds under Ionic Liquid Conditions
}

\author{
Ahmed Ali Hullio ${ }^{1}$ \& G. M. Mastoi ${ }^{2}$ \\ ${ }^{1}$ Dr. M. A. Kazi Institute of Chemistry, University of Sindh Jamshoro, Pakistan \\ ${ }^{2}$ Department of Environmental Sciences, University of Sindh Jamshoro, Pakistan \\ Correspondence: Ahmed Ali Hullio, Dr. M. A. Kazi Institute of Chemistry, University of Sindh Jamshoro, \\ Pakistan. Tel: 92-222-7716-8190 ext.2004. E-mail: ahmedalihullio@yahoo.com
}

Received: March 6, 2013 Accepted: May 21, 2013 Online Published: July 15, 2013

doi:10.5539/ijc.v5n3p57 URL: http://dx.doi.org/10.5539/ijc.v5n3p57

\begin{abstract}
The ionic liquid based methylchloroiminium chloride reagent (Vilsmeier reagent) derived from DMF-like multipurpose functional ionic liquid has been used as an efficient and reusable reagent for Mitsunobu reaction. Variety of different alcohols has been converted into different classes of compounds under ionic liquid conditions. The present system offers a competitive and better alternative to routine Mitsunobu protocol.
\end{abstract}

Keywords: ionic liquid based Vilsmier reagent, DMF-like multipurpose functional ionic liquid, alcohols, Mitsunobu reaction

\section{Introduction}

The Mitsunobu reaction is a direct intermolecular or intramolecular substitution reaction of alcohols with weaker nucleophillic reagents mediated by diethyl azodicarboxylate (DEAD) and tri-coordinate phosphorus compounds, such as $\mathrm{Ph}_{3} \mathrm{P},\left(\mathrm{Me}_{2} \mathrm{~N}\right) \mathrm{P}$ etc. The Mitsunobu reaction has found wide spread use in many fields because of its high versatility and extensive applicability (Mitsunobu, 1981; Hughes, 1992, 1996). Since its introduction, the Mitsunobu reaction has been widely used for the re-functionalization of alcohols, as well as for inversion of hydroxyl group. Considerable bulk of research has been done to expand the scope of Mitsunobu reaction and it has been used to achieve key organic transformations and major steps in different total synthesis schemes. The immense interest of chemists in this reaction is also evident from the several reviews have been published (Swamy, B. Kumar, Balaraman, \& P. Kumar, 2009; Mitsunobu, 1981; Hughes, 1992).<smiles>[R]C([R])O</smiles>

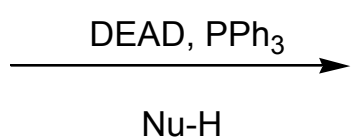<smiles>[R]C([R])[N]</smiles>

Scheme 1. General scheme for a Mitsunobu reaction

Mechanistically it is $\mathrm{S}_{\mathrm{N}} 2$ type substitution powered by a redox process in which phosphorus is oxidized and the azo group is reduced. The key feature of this reaction involves the use of an organocatalyst diethylazodicarboxylate (DEAD) which reacts with triphenylphosphine to form an intermediate complex (2b). The hydroxy group of alcohol reacts with positively charged phosphorus atom to from thermodynamically stronger P-O bond (2c) which converts the hydroxy group into an excellent leaving group which on reaction with any suitable nucleophile results in the facile substitution of hydroxyl group with that incoming nucleophile.

By the use of this procedure, alcohols can be successfully converted directly into variety of compounds depending upon the nature of attacking nucleophile (Scheme 1). Mitsunobu reactions transform primary and secondary alcohols into a variety of functional groups, such as esters, ethers, thioethers and several other compounds. The nucleophiles used can be acidic, basic or neutral. The commonly used stronger and weaker nucleophiles such as carboxylic acids, hydrazoic acid, imide, phenol and thiol on reaction with alcohols under 
Mitsunobu reaction give ester, alkyl azide, substituted imide, alkyl aryl ether, substituted sulfonamide and thioether respectively. The intramolecular variant of these reactions afford various cyclic compound such as aziridines, lactones and lactams etc. Therefore, the Mitsunobu reaction has been widely used in organic synthesis, especially in the synthesis and transformations of various natural products (Mitsunobu, 1981).

Keeping in view the importance of this reaction, its scope has been extended constantly and relevant modifications have been introduced. However certain key procedural drawbacks continue to create handling issues. The major problem inflicting the Mitsunobu reaction is tedious work up procedure especially the isolation of product. The generation of phosphine oxide and hydrazinodicarboxylate as by-products often prevents the isolation of desired product in pure form. Various ways of addressing this problem have been developed including triphenylphosphine (TPP) analogues that can be either removed by acid wash (Camp \& Jenkins, 1988; von Itzstein \& Mocerino, 1990; Camp, 1988; von Itzstein, 1990) or anchored to a resin (Amos, Emblidge, \& Havens, 1983; Bernard \& Ford, 1983; Tunoori, Dutta, \& Georg, 1998). The latter has also been applied to derivatives of dialkyl azodicarboxylates (Arnold, Assil, \& Vederas, 1989). A new method that removes impurities via the novel ring opening metathesis (ROM) protocol has been developed (Barrett \& Schroder, 2000). Alkyl phosphines have also been introduced as a replacement for TPP. However, these compounds are highly expensive or pyrophoric. Barrett et al. have described the use of phosphites that would generate phosphates, which are more water soluble than their counterpart phosphine oxides (Beller \& Zapf, 1998; Zapf \& Beller, 2000; Kayaki, Koda, \& Ikariya, 2004). Another option involves the use of resin-bound triphenylphoshine and di-tert-butylazodicarboxylate instead of DEAD. The oxidized triphenylphosphine resin can be removed by filtration, and the di-tert-butylazodicarboxylate by-product is removed by treatment with trifluoroacetic acid (Pelletier \& Kincaid, 2000). Lipshutz, Chung, Rich, and Corral (2006) has developed an alternative to DEAD, Di-(4-chlorobenzyl)azodicarboxylate (DCAD) where the hydrazine by-product can be easily removed by filtration and recycled back to DCAD. A modification has also been reported in which DEAD can be used in catalytic versus stoichiometric quantities. However, this procedure requires the use of stoichiometric (diacetoxyiodo) benzene to oxidize the hydrazine by-product back to DEAD (Poupon, Boezio, \& Charette, 2006). The ylide acts as both the reducing agent as well as the base. The by-products are acetonitrile and the trialkylphosphine oxide. Apart from tedious work up the excessive use of expensive reagents make it costly, and generation of toxic waste products render it environmentally unfavorable. In addition to this, maintenance of relevant reaction conditions i.e. freezing temperature and inert atmosphere is daunting task. Longer reaction times and poor yields present quite dismal situation. Notwithstanding its popularity, research continues to address various aspects of Mitsunobu chemistry and its modification evolves with time.

Ionic liquids are unique class of compounds with unusual combination of physical properties. They are no more a new field of research in the area of green chemistry and organocatalysis etc (Hullio \& Mastoi, 2011b). Interesting blend of properties has led to their ever expanding applications in various fields of the applied chemistry. More importantly the task specific ionic liquid is special types of ionic liquids in which an organocatalyst is anchored on imidazolium ring in order to perform ordinary organocatalysed reaction under ionic liquids. This strategy leads to many advantages like green conditions, operational convenience and efficient results in terms of higher yields within less time. The commonly reported task specific functional ionic liquids are designed for one specific task i.e. reaction. In contrast to this, Hullio et al. introduced a novel concept of multipurpose functional ionic liquid which can be used to achieve diverse range of chemical transformations (Hullio \& Mastoi, 2011c, 2012a, 2012b, 2012d, 2012e). Keeping in view the active role of DMF on influencing the course of certain reactions, we have reported DMF-like functional ionic liquid in which DMF moiety was attached to imidazolium ring through chain two carbons. The DMF-like functional ionic liquid has been shown to accomplish many different types of chemical reactions and thus has earned a new title called "multipurpose" ionic liquid instead of "task specific" ionic liquid. One of the remarkable applications of DMF-like multipurpose functional ionic liquid is the preparation of ionic liquid version of Vilsmeier reagent (Hullio \& Mastoi, 2012e) which has revolutionarized the potential of applications of Vilsmeier reagent. It is highly reactive electrophillic specie having potential of catalyzing many electrophillic reagent dependent reactions.

The use of Vilsmeier reagent for Mistunobu reaction has been known (Procopiou, Brodie, Deal, \& Hayman, 1993) for several decades. In continuation of our search for applications of novel "multipurpose" DMF-like multipurpose functional ionic liquid, we have already reported the synthesis and applications of ionic liquid version of Vilsmeier reagent and its applications (Hullio \& Mastoi, 2012e). On further exploration of the applications of our ionic liquid-based Vilsmeier reagent, we decided to investigate its potential as a substitute to ordinary Mitsunobu reagent. Our goal was to develop a new solution-based reagent that offers the important feature of straight forward separation and recovery of the products based on biphasic separation. Such a reagent 
not only would facilitate the purification of the desired product but also recycling of reagent to avoid the formation of chemical waste.

We can predict the outcome of our novel methodology by comparing the driving forces involved in routine Mitsunobu protocol with those involved with use of ionic liquid-based Vilsmeier reagent. The routine Mitsunobu reaction is $\mathrm{S}_{\mathrm{N}}^{2}$ substitution which is powered by a redox process in which phosphorus is oxidized and the azo group is reduced and the main driving force in this case is formation of oxygen phosphorus double bond (Scheme 2).

A reasonable mechanism suggests the attack of triphenylphosphine on nitrogen of the azodicarboxylate with subsequent protonation of adjacent nitrogen. Then hydroxyl group of alcohol attacks the phosphonium intermediate forming thermodynamically stable $\mathrm{P}-\mathrm{O}$ bond. In this way $-\mathrm{OH}$ group is converted into a good leaving group (Scheme 2).<smiles>[Y]OC(=O)N=NN(CC)C(=O)O[X]</smiles>

(2a)

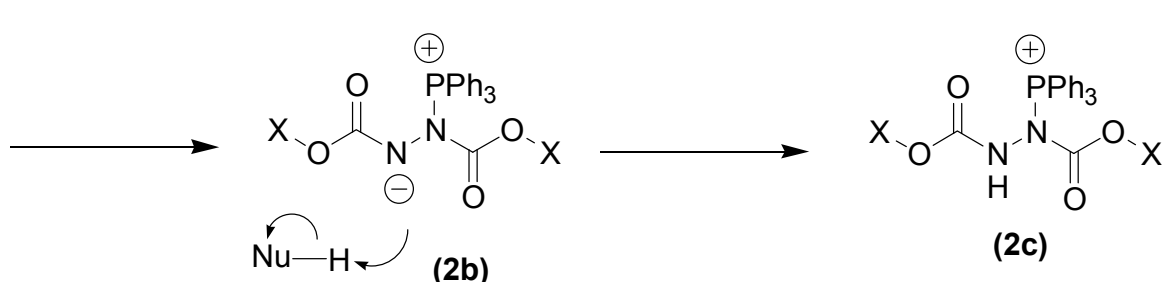<smiles>[X]OC(=O)Nn1on([R6]2CCCCCCC2[R])c1=O</smiles>

(2d) (2e)<smiles>[CH]</smiles>

$$
\text { an) }
$$<smiles>[R]C(CC)O[Sb]</smiles><smiles>[X]OC(=O)NNC(=O)O[X]</smiles>

(2f)<smiles>[X]OC(=O)NNC(=O)O[V]</smiles>

(2h)

Scheme 2. Mechanism involving the DEAD promoted direct substitution of hydroxyl group

In case of our ionic liquid based Vilsmeier reagent the driving force emanates from two key factors i.e. firstly the marginal stabilization of charged intermediates formed during reaction by strong solvation effects of ionic liquid. Secondly, the removal of positive charge from nitrogen with restoration of its lone pair and formation of $\mathrm{C}=\mathrm{O}$ double of carbonyl group in Vilsmeier reagent after reaction. These features are evident from mechanism depicted in (Scheme 3). 
<smiles></smiles><smiles></smiles>

Scheme 3. The proposed mechanism involved in ionic liquid based choloroiminium reagent promoting Mitsunobu reaction

Since all applications of ionic liquid based Vilsmeier reagent reported so far involves the use of alcohols as reactants for various transformations and in most of cases the hydroxy group was found to be the main nucleophillic group attacking the Vilsmeier reagent triggering the rest of reaction, this made us think of using the same ionic liquid reagent as substitute for ordinary Mitsunobu protocols (Scheme 4).

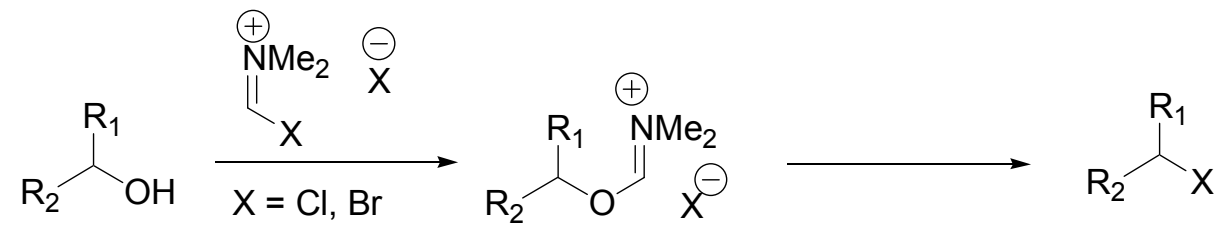

Scheme 4. Vilsmier reagent promoting alcohol based reactions

Ionic liquid based Vilsmeier reagent can replace the Mitsunobu reagent providing the procedural convenience, green reaction condition, rapid and efficient conversions, and easy isolation of products. Thus in this paper, we are describing the full experimental details of preparation of ionic liquid Vilsmeier reagent from DMF-like multipurpose functional ionic liquid and methods development for experiments of the different tests and their scope.

\section{Experimental}

\subsection{Material}

All the reagents and solvents were pure and of analytical grade chemicals purchased from Aldrich and were used without further purification. Melting/boiling points were determined with a Buchi 510 melting point apparatus (Flawi/SG, Switzerland) and are uncorrected. Electron impact (EIMS) mass spectra were determined with a Finniggan MAT-312 (Bremen, Germany), Vrain MAT-112 (Bremen, Germany) double focusing mass spectrometer connected to a PDP $11 / 34$ (DEC) computer system. The ${ }^{1} \mathrm{HNMR}$ spectra were recorded in $\mathrm{CD}_{3} \mathrm{OD}$ and $\mathrm{CDCl}_{3}$ with Bruker AM 300 and 400 spectrometers (Rheinstetten-Forchheim, Germany) operating at 300 and $400 \mathrm{MHz}$, respectively. ${ }^{1} \mathrm{H}-\mathrm{NMR}$ chemical shifts are reported in $\delta(\mathrm{ppm})$ and coupling constants in Hz. The purity of the products was checked on TLC plates (Merck, Darmstadt, Germany), coated with silica gel PF254 and the spots were characterized with UV light at 254 and $366 \mathrm{~nm}$ and by spraying with ninhydrin and iodine tank. For GC, Agilent 6890 N Network System equipped with capillary column HP-5MS (30 m $\times 0.25 \mathrm{~mm}$ i.d., $0.25 \mu \mathrm{m}$ film thickness). The electron ionization (EI) mode at $70 \mathrm{eV}$ was used for MS detection. The temperature of oven was held at $90{ }^{\circ} \mathrm{C}$ for $1 \mathrm{~min}$, raised to $200{ }^{\circ} \mathrm{C}$ at $5{ }^{\circ} \mathrm{C} / \mathrm{min}(2 \mathrm{~min}$ hold $)$ and then to $280{ }^{\circ} \mathrm{C}$ at $20{ }^{\circ} \mathrm{C} / \mathrm{min}$ (12 min hold). $1 \mu \mathrm{L}$ sample was injected in hexane (HPLC grade), using splitless mode. The carrier gas Helium was used at a flow rate of $1.5 \mathrm{~mL} / \mathrm{min}$. The injector and MS transfer line temperature was set at 220 and $290{ }^{\circ} \mathrm{C}$, respectively. To calculate retention indices, solution of standard alkanes $\left(\mathrm{C}_{8}-\mathrm{C}_{32}\right)$ was analyzed using same conditions. 


\subsection{Reagent Preparation}

The required DMF-like multipurpose functional ionic liquid was prepared according to reported procedure (Hullio \& Mastoi, 2012c). It was converted into methylchloroiminium chloride reactive intermediate by treating the equimolar amount of DMF like ionic liquid with oxalyl chloride at $-10{ }^{\circ} \mathrm{C}$ (Scheme 5). The intermediate (3b) was characterized by ${ }^{1} \mathrm{HNMR}$. The thermal decomposition point of the ionic liquid was determined by TGA (Perkin-Elmer TGA Pyris1 instrument, $10{ }^{\circ} \mathrm{C} \mathrm{min}^{-1}$ heating rate under nitrogen) to be $235^{\circ} \mathrm{C}$.

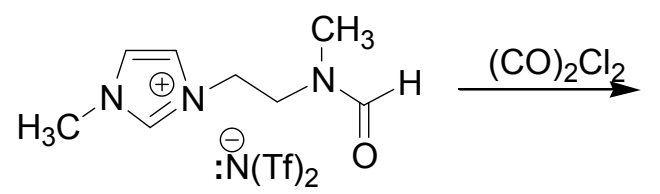

(3a)<smiles>C[N+](=O)[O-]</smiles>

(3b)

Scheme 5. Preparation of ionic liquid based Mitsunobu reagent

\subsection{Optimization of Reaction Conditions}

Normally the general procedure for Mitsunobu reaction involves treating the alcohol $(1 \mathrm{mmol})$ with excess of required nucleophile $(4 \mathrm{mmol})$, followed by addition of $\left(\mathrm{PPh}_{3}\right)(3.98 \mathrm{mmol})$, in dry THF under nitrogen in an ice bath. Then diethyl azodicarboxylate $(4 \mathrm{mmol})$ is added dropwise maintaining the temperature of reaction mixture below $10{ }^{\circ} \mathrm{C}$. Then solution is allowed to stir at room temperature for $14 \mathrm{hr}$ and subsequently at $40{ }^{\circ} \mathrm{C}$ for $3 \mathrm{hr}$. After completion of the reaction, the subsequent work up furnishes the required product. In this routine procedure the sequence of addition of reagents and maintenance of temperature seems to be critical for successful reaction.

In order to check the potential of our ionic liquid based methylchloroiminium reagent as a substitute to DEAD for Mitsunobu reaction, we initially chose isoamyl alcohol as a substrate. The ready-made ionic liquid based methylchloroiminium reagent $(1 \mathrm{mmol}, 0.482 \mathrm{mg})$ mixed with $2 \mathrm{~mL}$ of dry dichloromethane at $15{ }^{\circ} \mathrm{C}$. Then equimolar amount of isoamyl alcohol $(1 \mathrm{mmol}, 0.080 \mathrm{mg})$ was added dropwise to ionic liquid solution with constant stirring to ensure homogenous mixing and smooth formation of reactive complex i.e. substitution of hydroxy group with chloro group. Then the temperature of reaction mixture was raised to $25{ }^{\circ} \mathrm{C}$ and progress of reaction was monitored by gas chromatography (GC/MS) analysis till the completion of free isoamyl alcohol and formation of reactive complex. Then the complex was treated with 1 mole equivalent of benzoic acid $(1 \mathrm{mmol}$, $0.11 \mathrm{mg}$ ) in form of solution in $\mathrm{CH}_{2} \mathrm{Cl}_{2}$ and the resulting mixture was stirred at $25{ }^{\circ} \mathrm{C}$ and progress of reaction was monitored by GC/MS analysis. Rate of reaction was found to be slower i.e. $25 \%$ conversion for 45 minutes. In order to boost the reaction, we decided to raise the temperature to $35-40{ }^{\circ} \mathrm{C}$ which enhanced the rate of reaction and complete transformation was achieved with further 30 minutes.

The entire reaction was repeated with sodium salt of benzoate, a relatively stronger nucleophile than benzoic acid. A dramatic impact was found i.e. reaction was completed with 45 minutes by simply stirring at $25{ }^{\circ} \mathrm{C}$. Therefore reaction can be performed with two options i.e. using nucleophile with acidic hydrogen with stirring at $40{ }^{\circ} \mathrm{C}$ and using anionic salt of nucleophile with stirring the reaction mixture at $25^{\circ} \mathrm{C}$.

After completion of the reaction, the product was extracted with diethyl ether and dichloromethane was removed under vacuo. The remaining regenerated DMF-like ionic liquid was washed with distilled water to remove water soluble ions. This recovered ionic liquid was dried in oven at $80{ }^{\circ} \mathrm{C}$ then kept in desiccator. The products were characterized by GCMS data. The same reaction was repeated with phenol and sodium phenolate salt. Both forms of phenol gave better results as compared to benzoic acid and its salt.

\subsection{General Procedure for Ionic Liquid Based Methylchloroiminium Chloride Promoted Mitsunobu Reaction}

General Procedure for ionic liquid-based methylchloroiminium reagent promoted Mitsunobu reaction involves mixing the equimolar amount of an alcohol with ready-made ionic liquid based methylchloroiminium reagent in $5 \mathrm{~mL}$ of anhydrous dichloromethane. After homogenizing the reaction mixture, it was stirred magnetically at $25{ }^{\circ} \mathrm{C}$ and progress of reaction was monitored by GC/MS analysis till the complete formation of reactive complex. Then the complex was treated with 1 mole equivalent of nucleophile and the resulting mixture was stirred at $25{ }^{\circ} \mathrm{C}$ and then temperature was gradually raised from 40 to $45{ }^{\circ} \mathrm{C}$ and progress of reaction was monitored by GC/MS analysis. Most of reactions were completed within 40 to 60 minutes and some reaction 
took 2 to $3 \mathrm{hr}$. After completion of the reaction, dichloromethane was removed under vacuo and the product was extracted with diethyl ether. The remaining ionic liquid was washed with distilled water to remove water soluble ions. The recovered DMF-like ionic liquid was dried in oven at $80{ }^{\circ} \mathrm{C}$ then in desiccator. The products were characterized by GC/MS analysis data $\left(t_{R}\right.$ and $\left.\mathrm{m} / \mathrm{z}\right)$. Then we investigated the scope of this protocol for various structural variants of nucleophiles with alcohols. The data thus obtained is shown in (Tables 1 to 4 ).

\section{Results and Discussion}

After optimization of reaction conditions, we scrutinized the scope of present protocol from various aspects. This includes the nucleophillic power different commonly used nucleophiles such as alcohol, phenols, thiols, amines, imides, azides, cyanides, thiocyanides. To this end, different types of nucleophiles were treated with same alcohol under identical condition. Then we investigated the scope of this protocol for various structural variants of alcohols with same nucleophiles. We intended to see the response of various types of alcohols like primary, secondary, tertiary, allylic, and polyhydroxy alcohols etc. After this different types of appropriate combination of alcohols and nucleophiles were subjected to Mitsunobu type reaction under the present methodology. The intramolecular Mitsunobu reaction is very important reaction from synthetic point of view as it leads to heterocyclic ring formation. For this various substituted alcohols like diols, hydroxy acids, amino alcohols were studied and yielded the corresponding rings in quantitative amounts. The detail of each aspect given below and the data obtained are presented relevant table and described from various aspects.

\subsection{Different Nucleophiles with Same Alcohol}

Initially we decided to investigate the nucleophilicity of various commonly used nucleophiles under this novel protocol. For this purpose different types of nucleophiles were treated with same alcohol i.e. isoamyl alcohol. The nucleophiles are of two types acidic such as benzoic acid, phenol, thiols, imides and amides; the basic nucleophiles include amines, alkoxides and amides. And some neutral nucleophiles include cyanates, isocyanates and thiocyanates. The nucleophiles with acidic hydrogen were tested in both protonated as well as in deprotonated form. The data obtained is shown in (Table 1).

The data seems in conformity with theoretical prediction. The nucleophiles demonstrated their usual nucleophilicity trend.

\subsection{Different Types of Alcohols with Same Nucleophile}

In order to study the structural compatibility of different alcohols for a given nucleophile, we chose variety of primary, secondary and tertiary alcohols which were treated with sodium butanoate. The data presented in (Table 2) indicates the viable scope of present methodology for structural diversity of alcohol. Different types of alcohols displayed their typical chemistry with relatively enhanced efficiencies. The primary alcohols were found to be more responsive as compared to other alcohols and reactivity declined with increasing steric hindrance around hydroxyl group. Reason for using the butanoic acid in salt form was to exploit its maximum nucleophillic character.

\subsection{Different Types of Alcohols with Different Types of Nucleophiles}

Since wide range of nucleophiles and alcohols exists therefore any combination of these may be tested in our novel method. For this purpose we chose some of commonly used oxygen, nitrogen and sulphur based nucleophiles such as alcohol, hydrogen cyanide, hydrazoic acid, ethanthiol, isocyanic acid (HNCO) and an ambident nucleophile like the thiocyanate ion $\left(\mathrm{SCN}^{-}\right)$. These nucleophiles were tested with appropriate combination of alcohols. The choice of combination was selected with a view to widen the scope of current methodology. The data thus obtained is shown in (Table 3). Every nucleophile and alcohol maintained its typical chemical behavior but with faster reaction rates and relatively improved yields.

\subsection{Intramolecular Mitsunobu Reactions}

If any compound contains hydroxy group and other suitable nucleophillic centre within it at appropriate position with structural flexibility, such compound can undergo intramolecular Mitsunobu reaction under present protocol. For this study, we chose various hydroxy amines, hydroxy acids and diols. In each case of a given class of compound, the reaction started from 1,2 to 1,6 positioned groups producing a class of compounds with varying ring sizes. The rate of reaction was controlled by multiple factors i.e. nucleophilicity of attacking nucleophiles and length of ring to be formed. The data obtained is presented in (Table 4). The data indicates that for given chain length the rate of reaction decreased with different nucleophiles such as amino $>$ hydroxyl $>$ carboxyl group. In every class of compound, the rate of reaction increased with increasing chain of ring from 3 to 6 . 
Table 1. Mitsunobu reaction of different nucleophiles with isoamyl alcohol with ionic liquid based chloroiminium reagent

(2)

Yield (GC/MS) analysis. 
Table 2. Mitsunobu reaction of different alcohols with same nucleophiles with ionic liquid based chloroiminium reagent

Entry

Yield (GC/MS) analysis. 
Table 3. Mitsunobu reaction of different alcohols with different nucleophiles with ionic liquid based chloroiminium reagent

(2)

Yield (GC/MS) analysis. 
Table 4. Intramolecular Mitsunobu reactions with ionic liquid-based chloroiminium reagent

\begin{tabular}{|c|c|c|c|c|}
\hline Entry & Substrate & Product & $\begin{array}{c}\text { Time } \\
\text { (h) }\end{array}$ & $\begin{array}{c}\text { Yield } \\
(\%)\end{array}$ \\
\hline 1 & & & 3.0 & 72 \\
\hline 2 & & & 2.15 & 87 \\
\hline 3 & & & 2.30 & 83 \\
\hline 4 & & & 2.40 & 76 \\
\hline 5 & & & 2.0 & 89 \\
\hline 6 & & & 2.30 & 86 \\
\hline 7 & & & 2.20 & 81 \\
\hline 8 & & & 1.45 & 91 \\
\hline 9 & & & 1.30 & 90 \\
\hline 10 & & & 2.0 & 94 \\
\hline 11 & & & 2.0 & 85 \\
\hline
\end{tabular}

Yield (GC/MS) analysis.

\section{Recycling}

The one of the important aspect of green reagents is their recyclability. We investigated the opportunity of recovering and recycling of current methodology. The schematic representation of the catalytic cycle of ionic liquid based chloroiminium reagent is shown in (Scheme 6). 


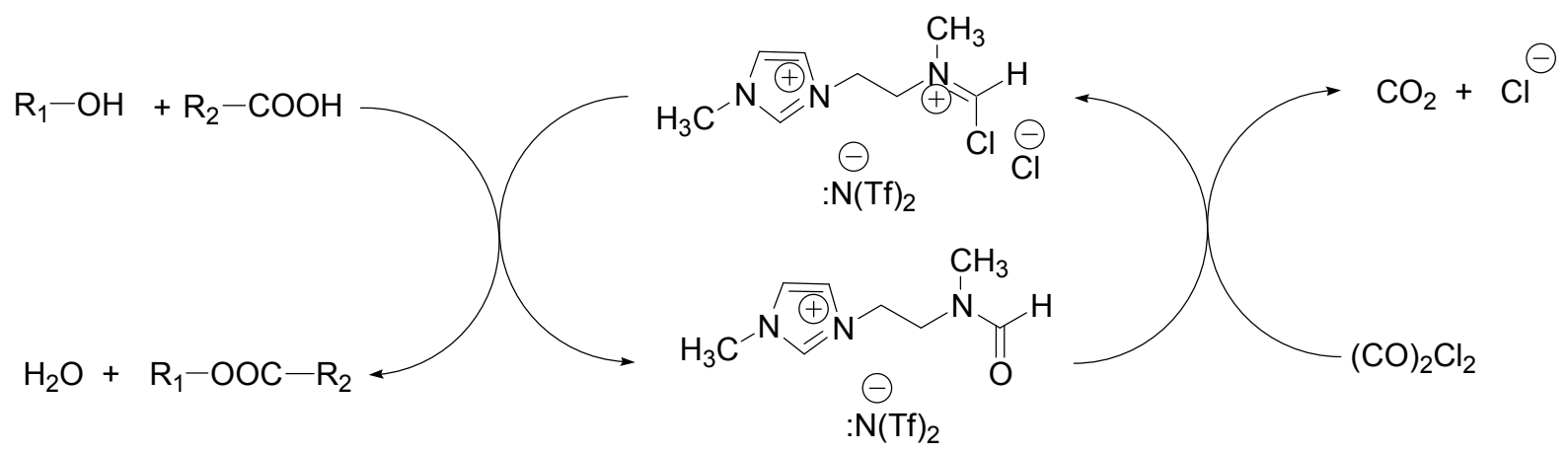

Scheme 6. Recycling of chloroiminium reagent in Mitsunobu reaction

For this purpose we used the Mitsunobu reaction of isoamyl alcohol with benzoic acid promoted by ionic liquid based Vilsmier reagent. The results are summarized in (Table 5), which show that the product yields are quite consistent up to seven recycles. The recovered ionic liquid maintains its catalytic efficiency up to ten recycles and this can extrapolated up to ten more recycling.

Table 5. Recycling studies of ionic liquid based chloroiminium reagent

\begin{tabular}{lcccccccccc}
\hline Recycling times & 1 & 2 & 3 & 4 & 5 & 6 & 7 & 8 & 9 & 10 \\
Product yield (\%) & 92 & 91 & 91 & 90 & 90 & 90 & 89 & 89 & 88 & 88 \\
Recovered ionic liquid (\%) & 100 & 100 & 98 & 98 & 98 & 98 & 97 & 97 & 97 & 97 \\
\hline
\end{tabular}

\section{Conclusion}

The ionic liquid-based Vilsmier reagent (3b) was found to be effective substitute of routine Mitsunobu protocol. Different aspects of this reaction were studies and data indicates the wide scope of current methodology and best alternative to routine procedure for Mitsunobu reaction. All types of reactions were found to be more rapid with improved yields under green conditions. The major draw backs inflicting the reported Mitsunobu protocols such as easy isolation of the product was eliminated in simplest way.

\section{Acknowledgments}

Authors gratefully acknowledge the financial support provided by the University of Sindh, and spectroscopic facilities offered by H.E.J international centre for biological and chemical sciences, University of Karachi-75270, Sindh Pakistan.

\section{References}

Amos, R. A., Emblidge, R. W., \& Havens, N. (1983). Esterification using a polymer-supported. phosphine reagent. J. Org. Chem., 48, 3598-3600. http://dx.doi.org/10.1021/jo00168a058

Arnold, L. D., Assil, H. I., \& Vederas, J. C. (1989). Polymer-supported alkyl azodicarboxylates for Mitsunobu reactions. J. Am. Chem. Soc., 111, 3973-3976. http://dx.doi.org/10.1021/ja00193a032

Barrett, A. G. M., \& Schroder, J. (2000). Impurity annihilation: Chromatograpy free parallel Mitsunobu reactions. Org. Lett., 2, 2999-3001. http://dx.doi.org/10.1021/o1006313g

Beller, M., \& Zapf, A. (1998). Phosphites as ligands for efficient catalysis of Heck reactions. Synlett., 792-793. http://dx.doi.org/10.1021/o1006313g

Bernard, M., \& Ford, W. T. (1983). Wittig reagents bound to cross-linked polystyrenes. J. Org. Chem., 48, 326-332. http://dx.doi.org/10.1021/jo00151a010

Camp, D., \& Jenkins, I. D. (1988). The use of a phosphine containing a basic group in the Mitsunobu esterification reaction. Aust. J. Chem., 41, 1835-1839. http://dx.doi.org/10.1071/CH9881835

Hughes, D. L. (1992). Organic Reactions (Vol. 42, pp. 335-656). New York: Wiley.

Hughes, D. L. (1996). Progress in the Mitsunobu reaction. A review. Org. Prep., 28, 127-164. 
http://dx.doi.org/10.1080/00304949609356516

Hullio, A. A., \& Mastoi, G. M. (2011b). Designing, synthesis and applications of task specific ionic liquids. Oriental J. of Chem., 27(4), 1591-1612.

Hullio, A. A., \& Mastoi, G. M. (2011a). Application of multipurpose dimethyl formamide-like task specific ionic liquid as a recyclable reagent for direct iodination of alcohols. Iranian Jr. of Catal., 1(2), 79-86.

Hullio, A. A., \& Mastoi, G. M. (2011c). First multipurpose task specific ionic liquids: Designing and synthesis of novel dimethyl formamide-like ionic liquid and its application as a green solvent alternative to dimethyl formamide dependent reactions. Asian J. of Chem., 23(12), 5411-5418.

Hullio, A. A., \& Mastoi, G. M. (2012a). Investigation of pyridine-catalyzed Huisgen cycloaddition reactions in nicotine-based task specific ionic liquid. Stud. J. Chem., 1(1), 27-48.

Hullio, A. A., \& Mastoi, G. M. (2012b). Nicotine-borane based task specific ionic liquid as an alternative reagent to pyridine-borane for efficient reductive amination. Stud. J. Chem., 1(2), 1-12.

Hullio, A. A., \& Mastoi, G. M. (2012c). Nicotine-based ionic liquid as a green and recyclable catalyst for Moritia Baylis-Hillman reaction. Jordan Jr. of Chem., 7(2), 125-138.

Hullio, A. A., \& Mastoi, G. M. (2012d). Nicotine-based ionic liquid: as a green catalyst for pyridine-catalyzed Huisgen reaction. Iranian Jr. of Catal., 2(4), 165-171.

Hullio, A. A., \& Mastoi, G. M. (2012e). Preparation of Ionic liquid version of Vilsmier reagent from novel multi-purpose dimethyl formamide-like ionic liquid and its application. Chin. Jr. of Chem., 30(7), 1647-1657.

Kayaki, Y., Koda, T., \& Ikariya, T. (2004). A highly effective (Triphenyl phosphite)palladium catalyst for a cross-coupling reaction of allylic alcohols with organoboronic acids. Eur. J. Org. Chem., 4989-4993. http://dx.doi.org/10.1002/ejoc.200400621

Lipshutz, B. H., Chung, D. W., Rich, B., \& Corral, R. (2006). Simplification of the Mitsunobu reaction. di-p-chlorobenzyl azodicarboxylate. Org. Lett., 8(22), 5069-5072. http://dx.doi.org/10.1021/o10618757

Mitsunobu, O. (1981). The use of diethyl azodicarboxylate and triphenylphosphine in synthesis and transfromation of natural products. Synthesis, 1-28. http://dx.doi.org/10.1055/s-1981-29317

Pelletier, J. C., \& Kincaid, S. (2000). Mitsunobu reaction modifications allowing product isolation without chromatography: Application to a small parallel library. Tetrahedron Lett., 41, 797-800. http://dx.doi.org/10.1016/S0040-4039(99)02214-5

Poupon, J.-C., Boezio, A. A., \& Charette, A. B. (2006). Tetraarylphosphonium salts as solubility-control groups: phosphonium-supported triphenylphosphine and azodicarboxylate reagents. Angew. Chem. Int. Ed., 45, 1415-1420. http://dx.doi.org/10.1002/anie.200503599

Procopiou, P. A., Brodie, A. C., Deal, M. J., \& Hayman, D. F. (1993). Novel cyclodehydration reaction of hydroxy-phenols using imidate esters as leaving groups. Tetrahedron Lett., 34(46), 7483-7486. http://dx.doi.org/10.1016/S0040-4039(00)60159-4

Swamy, K. C. K., Kumar, N. N. B., Balaraman, E., \& Kumar, K. V. P. P. (2009). Mitsunobu and related reactions: Advances and Applications. Chem Rev., 109, 2551. http://dx.doi.org/10.1021/cr800278z

Tunoori, A. R., Dutta, D., \& Georg, G. I. (1998). Polymer-bound triphenylphosphine as traceless reagent for Mitsunobu reactions in combinatorial chemistry: Synthesis of aryl ethers from phenols and alcohols. Tetrahedron Lett., 39, 8751-8754. http://dx.doi.org/10.1016/S0040-4039(98)01988-1

Von Itzstein, M., \& Mocerino, M. (1990). (4-Dimethylaminophenyl) diphenylphosphine: A more practical phosphine in the Mitsunobu reaction. Synth. Commun., 20, 2049-2057. http://dx.doi.org/10.1080/00397919008053136

Zapf, A., \& Beller, M. (2000). Palladium/Phosphite catalyst systems for efficient cross coupling of aryl bromides and chlorides with phenylboronic acid. Chem. Eur. J., 6, 1830-1833. http://dx.doi.org/10.1002/(SICI)1521-3765(20000515)6:10<1830::AID-CHEM1830>3.0.CO;2-8 


\section{Copyrights}

Copyright for this article is retained by the author(s), with first publication rights granted to the journal.

This is an open-access article distributed under the terms and conditions of the Creative Commons Attribution license (http://creativecommons.org/licenses/by/3.0/). 